\title{
Optimal therapeutic strategy for treating patients with hypertension and atherosclerosis: focus on olmesartan medoxomil
}

This article was published in the following Dove Press journal:

Vascular Health and Risk Management

23 June 2011

Number of times this article has been viewed

\section{R Preston Mason}

Cardiovascular Division, Brigham and Women's Hospital, Harvard Medical School, Boston, MA, and Elucida Research, Beverly, MA, USA
Correspondence: R Preston Mason 100 Cummings Center, Suite I35L, Beverly, MA 01915, USA

$\mathrm{Tel}+19788672125$

Fax + I 9789214195

Email rpmason@elucidaresearch.com
Abstract: Cardiovascular (CV) disease is a major factor in mortality rates around the world and contributes to more than one-third of deaths in the US. The underlying cause of CV disease is atherosclerosis, a chronic inflammatory process that is clinically manifested as coronary artery disease, carotid artery disease, or peripheral artery disease. It has been predicted that atherosclerosis will be the primary cause of death in the world by 2020. Consequently, developing a treatment regimen that can slow or even reverse the atherosclerotic process is imperative. Atherogenesis is initiated by endothelial injury due to oxidative stress associated with CV risk factors including diabetes mellitus, hypertension, cigarette smoking, dyslipidemia, obesity, and metabolic syndrome. Since the renin-angiotensin-aldosterone system (RAAS) plays a key role in vascular inflammatory responses, hypertension treatment with RAAS-blocking agents (angiotensin-converting enzyme inhibitors [ACEIs] and angiotensin II receptor blockers [ARBs]) may slow inflammatory processes and disease progression. Reduced nitric oxide (NO) bioavailability has an important role in the process of endothelial dysfunction and hypertension. Therefore, agents that increase NO and decrease oxidative stress, such as ARBs and ACEIs, may interfere with atherosclerosis. Studies show that angiotensin II type 1 receptor antagonism with an $\mathrm{ARB}$ improves endothelial function and reduces atherogenesis. In patients with hypertension, the ARB olmesartan medoxomil provides effective blood pressure lowering, with inflammatory marker studies demonstrating significant RAAS suppression. Several prospective, randomized studies show vascular benefits with olmesartan medoxomil: reduced progression of coronary atherosclerosis in patients with stable angina pectoris (OLIVUS); decreased vascular inflammatory markers in patients with hypertension and micro- (pre-clinical) inflammation (EUTOPIA); improved common carotid intima-media thickness and plaque volume in patients with diagnosed atherosclerosis (MORE); and resistance vessel remodeling in patients with stage 1 hypertension (VIOS). Although CV outcomes were not assessed in these studies, the observed benefits in surrogate endpoints of disease suggest that RAAS suppression with olmesartan medoxomil may potentially have beneficial effects on CV outcomes in these patient populations.

Keywords: angiotensin II receptor blocker, antihypertensive, atherosclerotic process, cardiovascular outcomes, coronary artery disease, olmesartan medoxomil, RAAS suppression

\section{Introduction}

More than 83 million adults in the US (over one-third) have cardiovascular disease (CVD). ${ }^{1}$ In 2007, mortality data showed CVD to be the underlying cause of death in $33.6 \%$ of all deaths in the US. ${ }^{1}$ Atherosclerosis, a progressive chronic inflammatory condition occurring in the walls of arteries, ${ }^{2}$ is the leading cause of CVD in the developed world, and atherosclerosis is predicted to be the primary cause of death worldwide by $2020 .{ }^{3}$ It is difficult to assess the exact frequency and prevalence of atherosclerosis. 
Typically, it is an asymptomatic condition that can begin as early as childhood, whereas symptomatic organ-specific clinical manifestations often do not appear until 40 years of age or older when it is most commonly diagnosed. ${ }^{4}$

Atherosclerosis is characterized by the formation of arterial lesions or plaques as a result of an inflammatory response to endothelial injury. ${ }^{5}$ The plaque primarily comprises macrophages, lipid-dense macrophages (foam cells), low-density lipoproteins, and neutral lipids, with subsequent calcification and ulceration appearing around the outer base of more mature plaques. ${ }^{67}$ Atherosclerosis eventually leads to artery enlargement, arterial stenosis (resulting in insufficient blood supply to the associated organ), and may ultimately produce an arterial rupture. ${ }^{7}$

Atherosclerosis can develop in any artery and, depending on the specific artery affected, can potentially develop into three main types of disease - coronary, carotid, or peripheral artery disease (PAD) ${ }^{8}$ In coronary artery disease (CAD), formation of an atherosclerotic plaque in a coronary artery may result in a myocardial infarction, whereas in carotid artery disease, formation of a plaque may lead to a stroke. ${ }^{8}$ Plaque formation in the arteries of the legs, arms, and/or pelvis leads to PAD, characterized by numbness, pain, and increased risk of infection and necrosis in the affected limb or region. ${ }^{8}$

Endothelial dysfunction is observed in the early stages of the atherogenic process, and it is initiated by injury to the arterial endothelium. Such injury has been associated with cardiovascular $(\mathrm{CV})$ risk factors including diabetes mellitus or impaired glucose metabolism, hypertension, cigarette smoking, dyslipidemia, obesity, and/or metabolic syndrome. ${ }^{9}$

Hypertension is an established risk factor for the development of atherosclerosis. ${ }^{10}$ Evidence suggests that hypertension both promotes and accelerates the atherosclerotic process via inflammatory mechanisms linked to activation of oxidative stress by angiotensin II (Ang II), which subsequently leads to endothelial dysfunction and development of atherogenic lesions and plaque. ${ }^{5}$

The purpose of this literature-based review is to present a current understanding of the mechanisms of the atherosclerotic process, including the roles of the renin-angiotensinaldosterone system (RAAS) and nitric oxide (NO). In addition, a summary of the efficacy of several antihypertensive drug classes in improving CV outcomes, endothelial function, and reducing the progression of atherosclerosis is presented. Finally, recent clinical trial data for the angiotensin II receptor blocker (ARB) olmesartan medoxomil, which focuses on the utility of RAAS suppression in reducing atherosclerosis and/ or improving endothelial function, is discussed.

\section{Mechanism of plaque formation in atherosclerosis}

The endothelium is responsible for the release and regulation of numerous vasoactive factors. In a disease-free state, the endothelium maintains these factors in homeostasis, resulting in normal control of vascular tone and function, as well as protecting against pro-atherogenic processes such as oxidation, monocyte adhesion, and the accumulation of lipids. ${ }^{11-13}$ However, initial injury to the endothelium, resulting from any of the abovementioned CV risk factors, alters the endothelial cell surface so that it becomes increasingly permeable and adhesive over time. Consequently, normal endothelial function becomes compromised and a series of cellular events are initiated, which ultimately results in the development of an atherosclerotic plaque. ${ }^{11}$

The increased permeability of arterial endothelial cells allows migration of low-density lipoprotein cholesterol (LDL-C) into the intima where it undergoes free radical oxidation. The presence of oxidized LDL-C then initiates an inflammatory response that includes the increased expression of circulating adhesion molecules including vascular cell adhesion molecule-1 (VCAM-1), intercellular adhesion molecule-1 (ICAM-1), endothelial-leukocyte adhesion molecule-1 (E-selectin), and P-selectin..$^{14}$ The presence of adhesion molecules and subsequent release of chemokines by macrophages, vascular smooth muscle cells (VSMCs), and endothelial cells results in the migration of peripheral leukocytes to the vascular wall.

Monocytes adhere to the endothelium via the interaction of adhesion molecules and infiltrate into the intima where they differentiate into macrophages, which is facilitated by proteins such as macrophage colony-stimulating factor. ${ }^{11}$ These macrophages then proceed to ingest the oxidized lipids via their scavenger receptors, thereby accumulating LDL-derived cholesterol esters. This process results in the formation of lipid-dense macrophage foam cells. ${ }^{11}$ Interactions between foam cells and T-helper 1 and 2 (Th1 and $\mathrm{Th} 2$ ) cells cause the release of various inflammatory molecules and cytokines, including interferon-gamma (IFN- $\gamma$ ), CD40 ligand, and interleukins (IL). ${ }^{15}$ Tumor necrosis factor (TNF)- $\alpha$, IFN- $\gamma$, and other cytokines then activate vascular endothelial cells, macrophages, and VSMCs. ${ }^{15}$ VSMCs proliferate and migrate from the media to the intima and accumulate along with the macrophages. Once there, interactions between T-helper cells, macrophages, and VSMCs 
stimulate secretion of additional inflammatory mediators, resulting in a chronic inflammatory response.

Advanced atherosclerotic lesions have a lipid-rich necrotic core due to the death of macrophages and VSMCs, and the continued release of lipids and other cellular components. ${ }^{16}$ Subsequent deposition of an interstitial fibrous matrix, composed of fibrin, collagen, and proteoglycans, results in the formation of a fibrous cap enclosing and stabilizing the underlying plaque. ${ }^{17}$

\section{Outcomes and potential consequences of plaque formation}

Following formation of a stable plaque, plaque destabilization can occur in the presence of one or more $\mathrm{CV}$ risk factors, particularly dyslipidemia. The vulnerable plaque can then rupture, resulting in platelet aggregation and thrombosis. ${ }^{6,16}$ The mechanisms of plaque destabilization are complex. ${ }^{18}$ Initially, macrophages release proinflammatory cytokines that precipitate changes in the plaque surface and create a prothrombotic state. ${ }^{19}$ Levels of protein-S and tissue plasminogen are reduced, and the release of metalloproteinases from macrophages and $\mathrm{T}$ cells, together with a reduction in collagen synthesis by VSMCs, results in degradation of the plaque's elastin and collagen fibrous cap. ${ }^{20}$ Simultaneous neovascularization occurs, resulting in further destabilization of the plaque and, ultimately, rupture. ${ }^{6}$ The main determinants of plaque vulnerability and rupture are related to their composition rather than size, and include lipid content and macrophage-related inflammation, as well as impaired healing and repair mechanisms. ${ }^{16}$

Following rupture, activation of the coagulation cascade, fibrin deposition, and platelet activation lead to the formation of a localized thrombus, which can cause obstruction of blood flow in the affected artery (arterial occlusion) and tissue ischemia. ${ }^{19}$ Plaque rupture can be fatal. If the plaque ruptures suddenly and is in a coronary artery, this can result in acute coronary syndrome (unstable angina, acute myocardial infarction, and/or sudden death). ${ }^{21}$ Alternatively, plaque rupture in a carotid artery leads to symptomatic carotid artery disease and increased risk of ischemic stroke. ${ }^{4}$

The endothelium possesses an endogenous regenerative capacity mediated primarily by bone marrow-derived endothelial progenitor cells. This repair process is ongoing and takes place after endothelial injury, both during plaque formation and after plaque rupture. However, the ability to undertake such repair and regeneration of damaged endothelium is adversely affected by $\mathrm{CV}$ risk factors, as shown by a marked reduction in the level of endothelial progenitor cells in high-risk patients. ${ }^{22}$

\section{Role of the renin-angiotensin- aldosterone system in inflammation and atherosclerosis}

In the nonpathological state, hemodynamic stability is preserved by the RAAS via the regulation of fluid balance and sodium levels, as well as direct and indirect vascular effects. ${ }^{15}$ However, excessive RAAS activity is associated with atherogenesis via its role in the initiation and maintenance of the vascular inflammatory response, and is implicated in the development of atherosclerosis and vascular events. ${ }^{15}$ Binding of Ang II, the major effector peptide of the RAAS, to the angiotensin II type $1\left(\mathrm{AT}_{1}\right)$ receptor produces a range of effects including vasoconstriction and both sodium and fluid retention. In addition, Ang II mediates both mitogenic and proliferative effects on vascular endothelial and smooth muscle cells. ${ }^{23}$

There is substantial evidence supporting the hypothesis that Ang II plays a significant role in the initiation and progression of atherogenesis. ${ }^{24}$ For example, the recruitment of inflammatory cells to injured arteries by Ang II is one of the initial events in atherogenesis. Inflammatory cells at the site of injury then subsequently produce Ang II, resulting in a positive feedback loop that perpetuates a proinflammatory cycle. ${ }^{15}$ In addition, Ang II-related mechanisms have been implicated in arterial fibrosis, ${ }^{25}$ endothelial dysfunction, ${ }^{26}$ oxidative stress, ${ }^{24}$ and plaque instability. ${ }^{27}$

\section{Role of nitric oxide in atherosclerosis}

The endothelium is also responsible for the release and regulation of numerous vasoactive substances, including NO. NO mediates the relaxation and vasodilation of VSMCs; prevents leukocyte adhesion and migration into the arterial wall; inhibits platelet activation, adhesion, and aggregation; and inhibits VSMC proliferation. ${ }^{9,29}$

Impaired NO bioavailability has been shown to play an important role in the process of endothelial dysfunction ${ }^{9}$ and subsequent atherogenesis. ${ }^{29}$ Oxidative stress generated by $\mathrm{CV}$ risk factors is a major cause of NO inactivity, ${ }^{30}$ creating an imbalance that results in increased levels of superoxide anions $\left(\mathrm{O}_{2}^{-}\right)$. All $\mathrm{CV}$ risk factors increase levels of reactive oxygen species (ROS; or oxygen-derived free radicals). For example, in patients with hypertension, the main source of oxygen-derived free radicals is the cyclooxygenase (prostanoid) pathway. ${ }^{31,32}$ Subsequent increased reactions between 
NO and superoxide anions create the highly reactive oxidant peroxynitrite $\left(\mathrm{ONOO}^{-}\right) .{ }^{33}$ Loss of $\mathrm{NO}$ bioavailability is associated with enhanced levels of endothelin-1 and Ang II. These factors contribute to reduced vasodilation, increased adhesion of platelets and leukocytes at the site of endothelial injury, VSMC migration and proliferation, and deposition of lipids into the intima. ${ }^{12,13,29,34}$

Endothelial dysfunction itself has been shown to be directly associated with hypertension, and is thought to contribute to functional abnormalities in resistance vessels (eg, impaired endothelial-dependent vasodilation) observed in patients with hypertension. ${ }^{35,36}$ Not only is free radical-related reduction in NO bioavailability a major cause of endothelial dysfunction in patients with hypertension, but it is thought that oxidative stress could be a common mechanism of endothelial dysfunction associated with other CV risk factors. ${ }^{31}$

\section{Restoration of vascular function with antihypertensive agents: clinical data and mechanism of action studies}

Antihypertensive agents that increase NO, decrease oxidative stress, and/or reduce RAAS-associated inflammation have been shown to slow the progression of the atherogenic process. ${ }^{37,38}$

ARBs and angiotensin-converting enzyme inhibitors (ACEIs) are agents that directly affect the RAAS, either by blocking the binding of Ang II to the $\mathrm{AT}_{1}$ receptor or decreasing the production of Ang II, respectively, and therefore may be beneficial in treating patients with atherosclerosis. ${ }^{37}$ These RAAS antagonists, as well as some dihydropyridine calcium channel blockers (CCBs), possess ancillary and synergistic effects that increase NO bioavailability, reduce oxidative stress, and suppress inflammatory responses, thereby improving both endothelial activity and vascular function. ${ }^{39}$

\section{ACEls and CCBs: effect on CV outcomes in high-risk patients}

Several large, long-term clinical studies have investigated the effect of ACEIs and CCBs on CV outcomes in high-risk patients. ${ }^{36}$ The HOPE (Heart Outcomes Prevention Evaluation) study was a $2 \times 2$ factorial trial undertaken in 9297 patients aged $\geq 55$ years at high risk of adverse CV outcomes (existing vascular disease or diabetes plus one other $\mathrm{CV}$ risk factor, but no reduction in ejection fraction or heart failure was required). HOPE compared the ACEI ramipril $10 \mathrm{mg}$ once daily vs placebo over 5 years for effect on the primary study outcome - composite of myocardial infarction, stroke, or death from $\mathrm{CV}$ causes. ${ }^{40}$ The HOPE findings demonstrated that ramipril significantly improved the rate of the primary composite endpoint vs placebo (14.0\% vs $17.8 \% ; P<0.001)$. Ramipril also improved rates of individual endpoints significantly more than placebo (all $P \leq 0.005$ ). These effects were thought to be mainly independent of blood pressure (BP) reduction since the majority of patients did not have hypertension at baseline, and the mean BP reduction was very low. ${ }^{40}$

The effect of amlodipine on the progression of atherosclerosis and the occurrence of clinical CV events was determined in 825 patients with angiographically documented CAD in the PREVENT (Prospective Randomized Evaluation of the Vascular Effects of Norvasc Trial) study. ${ }^{41}$ In PREVENT, amlodipine significantly slowed the 36-month progression of atherosclerosis in carotid arteries as assessed by B-mode ultrasonography; intima-media thickness (IMT) decreased by $0.0126 \mathrm{~mm}$ in the amlodipine-treated patients compared with an increase of $0.033 \mathrm{~mm}$ in the placebo group $(P=0.007$ vs placebo $) .{ }^{41}$

The CAMELOT (Comparison of Amlodipine vs Enalapril to Limit Occurrences of Thrombosis) study showed that in patients with normal BP (mean baseline BP $=129 / 78 \mathrm{mmHg}$ ) and documented $\mathrm{CAD}$, amlodipine therapy resulted in a significant reduction in adverse $\mathrm{CV}$ events vs placebo $(P=0.003)$, and a trend toward reduced progression of atherosclerosis vs placebo $(P=0.12)$. In a subgroup of patients with baseline systolic BP greater than the mean, the rate of atherosclerosis progression was significantly lower with amlodipine compared with placebo $(P=0.02)$. A trend towards a correlation between $\mathrm{BP}$ reduction and progression of atherosclerosis was observed $(P=0.07) .{ }^{42}$

SECURE (Study to Evaluate Carotid Ultrasound Changes in Patients Treated With Ramipril and Vitamin E) was a randomized, double-blind substudy of the HOPE trial in 732 patients aged $\geq 55$ years with vascular disease or diabetes, and at least one other CV risk factor. In addition, patients could not have heart failure or a low left ventricular ejection fraction. SECURE demonstrated that the rate of progression of the mean maximum carotid artery IMT was significantly lower in the ramipril $10 \mathrm{mg}$ once-daily treatment group vs placebo $(P=0.028)$ over an average follow-up period of 4.5 years. The difference in mean IMT progression between ramipril and placebo remained significant $(P<0.05)$ after adjustment for BP changes and after multivariate adjustment. ${ }^{43}$

\section{Mechanisms of action}

The mechanisms of action behind the improvement in $\mathrm{CV}$ outcomes reported with ACEIs and CCBs are not 
fully understood. ACEIs are known to interfere with the breakdown of bradykinin, which stimulates NO release. ${ }^{9}$ ACEIs also inhibit the production of endothelin-1 and Ang II by the endothelium, which reduces the production of superoxide anion, further increasing the levels of available NO. ${ }^{44}$ Mechanistic studies have shown that in patients with hypertension, vessel wall elasticity is improved and arterial stiffness reduced by calcium channel or RAAS blockade, ${ }^{39}$ as shown by a significant reduction in the central aortic augmentation index. ${ }^{45,46}$ Long-acting CCBs, eg, amlodipine, are also known to protect against oxidation of low-density lipoprotein (LDL) and membrane lipids via their antioxidant effects, which are independent of BP lowering. ${ }^{47}$

\section{Mechanisms and clinical effect of ARBs on endothelial function and atherosclerosis}

Figure 1 shows some of the known effects on the mechanisms of atherosclerosis resulting from the binding of Ang II to the $\mathrm{AT}_{1}$ receptor. ${ }^{48}$ Clinical trials have demonstrated that ARBs can improve endothelial function and/or reduce markers of atherosclerosis via $\mathrm{AT}_{1}$ receptor antagonism. Candesartan improves endothelial function as evidenced by significantly increasing flow-mediated dilation in patients with hypertension, stable CAD, and endothelial dysfunction. ${ }^{49}$ Candesartan significantly improves the percent flow-mediated dilator response to hyperemia ( $P=0.019$ ); significantly decreases plasma levels of plasminogen activator inhibitor type-1 (PAI-1) antigen $(P<0.001)$ as well as monocyte chemoattractant protein-1 $(P=0.004),{ }^{50}$ and significantly reduces circulating levels of ICAM-1 and VCAM-1 $(P<0.05) .{ }^{51}$ Candesartan has also been shown to slow the progression of carotid remodeling in patients with hypertension and type 2 diabetes. ${ }^{52}$ Experimental in vitro and in vivo studies with candesartan suggest that a possible mechanism of action for the anti-inflammatory effect seen with ARBs may include the suppression of toll-like receptor (TLR) 2 and TLR4 expression. ${ }^{53}$ TLR 2 and TLR4 are thought to participate in the inflammatory process of atherosclerosis. ${ }^{2}$

Clinical studies have shown that in patients with hypertension, irbesartan significantly increases endothelium-dependent and endothelium-independent vasodilation while significantly decreasing plasma endothelin $(P=0.001)$ and restoring the vasoconstriction capacity of NOS inhibitors. ${ }^{54,55}$ Irbesartan has also been shown to reduce fibrinogen and thrombomodulin; ${ }^{56}$ PAI-1 $;{ }^{56,57}$ nitrotyrosine $;{ }^{58}$ C-reactive protein (CRP), ICAM-1, and IL- $6 ;^{57,58}$ and plasma levels of 8-isoprostane (a marker of oxidative stress). ${ }^{57}$ In addition, clinical data demonstrate that irbesartan significantly increases flow-mediated

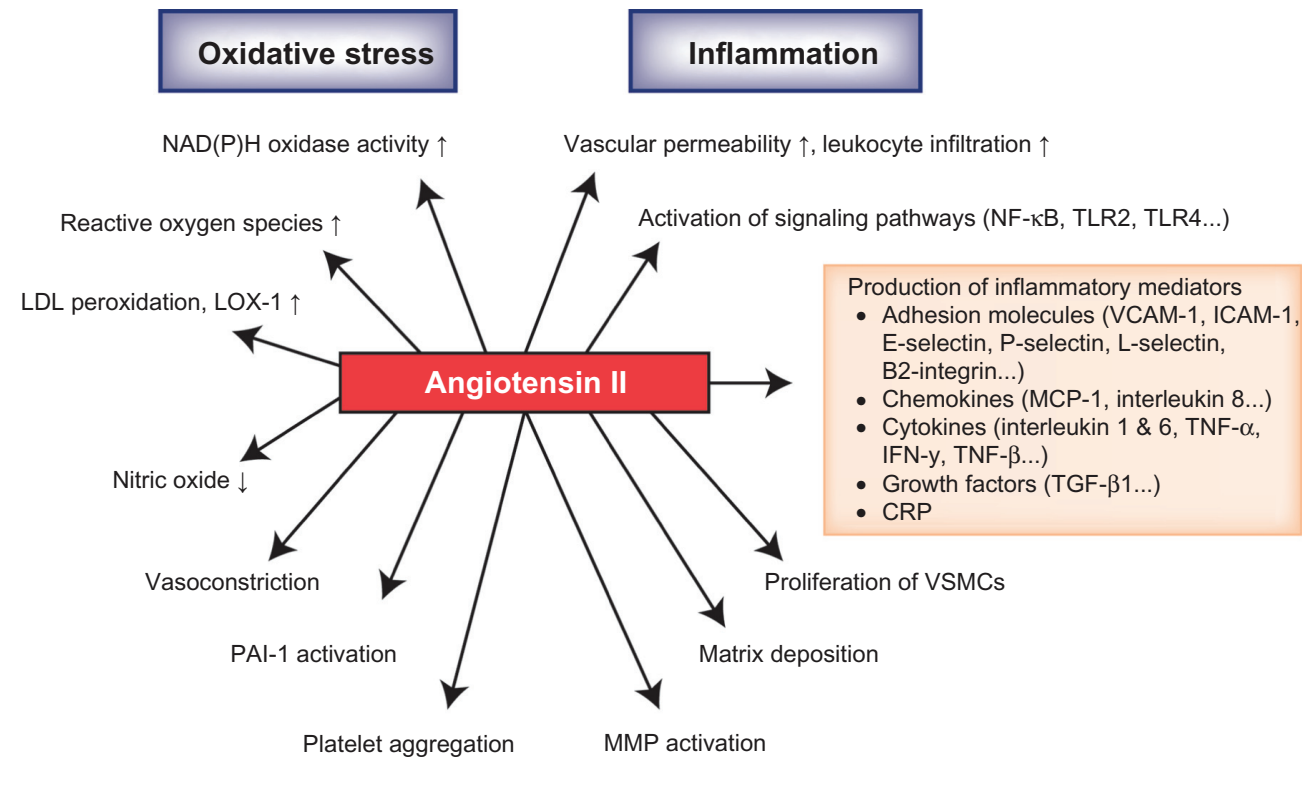

Endothelial dysfunction

Tissue remodeling

Figure I Effects of angiotensin II on the mechanisms associated with the arthrosclerotic process.

Abbreviations: CRP, C-reactive protein; ICAM-I, intercellular adhesion molecule-I; IFN- $\gamma$, interferon-gamma; LDL, low-density lipoprotein; LOX-I, lectin-like oxidized LDL receptor; MCP-I, monocyte chemoattractant protein-I; MMP, matrix metalloproteinase; PAI-I, plasminogen activator inhibitor type-I; TGF- $\beta$ I, transforming growth factor-beta-I; TNF, tumor necrosis factor; TLR, toll-like receptor; VSMCs, vascular smooth muscle cells; VCAM-I, vascular adhesion molecule-I.

Reprinted from Schmieder RE, et al. Renin-angiotensin system and cardiovascular risk. The Lancet. 2007;369:1208-1219. Copyright with permission from Elsevier. ${ }^{48}$ 
vasodilation..$^{57,58}$ Overall, blockade of the RAAS by irbesartan has been shown to improve endothelial function beyond that expected by BP lowering alone. ${ }^{59}$

In patients with hypertension, losartan has been shown to prevent the production of connective tissue growth factor and transforming growth factor- $\beta$ (known mediators of Ang II-induced remodeling of resistance arteries) as well as improve the media:lumen ratio in resistance arteries. ${ }^{60}$ Furthermore, clinical trial data demonstrate that losartan can attenuate the oxidation of LDL $(P=0.001)$ in patients with type 2 diabetes,${ }^{61}$ significantly reduce 8 -isoprostane $(P=0.01),{ }^{62}$ and significantly decrease common carotid artery IMT $(P<0.05){ }^{63}$

Several valsartan studies have demonstrated RAAS suppression and an associated reduction in inflammation. Valsartan has been shown to significantly suppress the generation of ROS in polymorphonuclear and mononuclear cells of normal subjects $(P<0.01)$. It has also been shown to suppress the activity of NF-KB binding activity $(P<0.01)$, which is responsible for regulating the transcription of genes for proinflammatory cytokines, adhesion molecules, chemokines, and protein subunits of ROS-generating enzymes. Valsartan significantly increased the expression of inhibitor $K \mathrm{~B}(P<0.05)$, which binds to NF- $K \mathrm{~B}$ and prevents it from translocating into the nucleus, thus preventing transcription of proinflammatory genes, and has also been shown to significantly decrease plasma CRP concentration $(P<0.01){ }^{64}$ Furthermore, valsartan significantly reduced TNF- $\alpha(P=0.006)$ and IL-6 $(P=0.005)$ in patients with essential hypertension. ${ }^{65}$

The mechanism of the anti-inflammatory effects of telmisartan was investigated in a 12-week, double-blind, placebo-controlled study in patients with hypertension and CAD. A range of inflammatory markers were assessed, ie, high-sensitivity CRP (hsCRP), IL-6, and cell adhesion molecules, soluble ICAM-1, leukocyte adhesion molecule soluble-L-selectin, and the $\beta 2$ integrin Mac-1; however, only Mac-1 expression was significantly decreased by telmisartan. ${ }^{66}$ Associated in vitro studies conducted to elucidate the mode of action showed that telmisartan dose-dependently inhibited $\beta 2$-integrin expression in lymphocytes in either the absence or presence of Ang II, suggesting that the atheroprotective effects associated with telmisartan are independent of the $\mathrm{AT}_{1}$ receptor. ${ }^{66}$

\section{Studies investigating the anti-atherogenic mechanism of action of olmesartan medoxomil}

The ARB olmesartan medoxomil has demonstrated effective BP lowering in numerous clinical trials with a tolerability profile similar to that of placebo. ${ }^{67}$ Moreover, olmesartan medoxomil has been shown to be efficacious across a wide range of patient subgroups. ${ }^{68,69}$ In vitro and in vivo animal studies have suggested anti-atherogenic and anti-inflammatory effects of olmesartan medoxomil. In an in vitro study investigating the effect of olmesartan on Ang II-induced migration of VSMCs from the rat aorta, data showed olmesartan to be a potent inhibitor of VSMC migration, with the inhibitory effect being mediated via Src- and mitogenactivated protein kinase pathways. ${ }^{70}$

These findings suggest that olmesartan medoxomil may potentially prevent vascular remodeling associated with VSMC migration. In addition, animal studies have demonstrated the effects of olmesartan on the suppression or regression of fatty streak plaque,,$^{71,72}$ and reduction of superoxide generation and overload of oxidative stress on the aortic walls. $^{71}$ In vitro experiments have shown that olmesartan also suppressed levels of IFN- $\gamma$, macrophage inflammatory protein-2, and thioredoxin (a marker of oxidative stress) in cultured cells. $^{71}$

\section{Clinical effect of olmesartan medoxomil on endothelial function \\ and atherosclerosis}

Study data from several recent olmesartan medoxomil clinical trials demonstrate the utility of RAAS suppression in reducing atherosclerosis and/or improving endothelial function. ${ }^{73-76}$ These studies are summarized in Table 1.

\section{OLIVUS}

The most recent of these trials was the OLIVUS (Impact of Olmesartan on Progression of Coronary Atherosclerosis: Evaluation by Intravascular Ultrasound) study, which was a prospective, randomized trial designed to assess the effect of olmesartan medoxomil on the progression of coronary atherosclerosis. ${ }^{73}$ More specifically, this study evaluated the effect of olmesartan medoxomil on coronary atherosclerotic changes assessed by volumetric intravascular ultrasound (IVUS) in 247 patients with stable angina pectoris with native CAD. Patients were randomly assigned to receive olmesartan medoxomil 10, 20, or $40 \mathrm{mg}$ or control (placebo), and also received a combination of $\beta$-blockers, CCBs, diuretics, nitrates, glycemic control agents, and/or statins, according to their physician's guidance (Table 1). Serial IVUS examinations were performed at baseline and at 14 months to assess coronary atheroma volume. IVUS was performed in nonculprit vessels (without angiographically documented coronary stenosis; $<50 \%$ ) when patients underwent percutaneous 
Table I Olmesartan medoxomil (OM) studies investigating the utility of renin-angiotensin-aldosterone system suppression in reducing atherosclerosis and/or improving endothelial function

\begin{tabular}{|c|c|c|c|c|c|}
\hline $\begin{array}{l}\text { Study } \\
\text { name }\end{array}$ & $\begin{array}{l}\text { Design } \\
\text { (duration) }\end{array}$ & Interventions & Patients (n) & Endpoints & Results \\
\hline OLIVUS $^{73}$ & $\begin{array}{l}\mathrm{P}, \mathrm{R} \\
(\mathrm{I} 4 \mathrm{mo})\end{array}$ & $\begin{array}{l}\text { OM I0, 20, or } 40 \mathrm{mg} / \mathrm{d} \\
\text { PLA } \\
\text { (+ } \beta \text {-blockers, CCBs, } \\
\text { diuretics, nitrates, } \\
\text { antiglycemics, } \\
\text { and/or statins prn) }\end{array}$ & $\begin{array}{l}\text { Stable angina with } \\
\text { native CAD (247) }\end{array}$ & $\begin{array}{l}\text { Vascular morphology: } \\
\text { lumen, plaque, vessel } \\
\text { volume, PAV, and TAV } \\
\text { assessed by IVUS in } \\
\text { nonculprit vessels } \\
\text { during PCI }\end{array}$ & $\begin{array}{l}\text { Significantly greater } \\
\text { improvement in TAV } \\
\text { and PAV with OM vs PLA } \\
(P<0.05)\end{array}$ \\
\hline EUTOPIA ${ }^{76}$ & $\begin{array}{l}P, D B, R \\
(12 w k)\end{array}$ & $\begin{array}{l}\text { OM } \\
\text { PLA } \\
(+\mathrm{HCTZ} 12.5 \text { or } \\
25 \mathrm{mg} / \mathrm{d} \text { prn } \\
\text { and pravastatin } 20 \mathrm{mg} \\
\text { od at wk 6) }\end{array}$ & $\begin{array}{l}\mathrm{HTN} \text { and } \\
\text { microinflammation }(2 \mathrm{II})\end{array}$ & $\begin{array}{l}\text { Inflammatory markers } \\
\text { Primary: hsCRP, hsTNF- } \alpha \text {, } \\
\text { IL-6, ICAM-I, and } \\
\text { MCP at } 6 \text { wk } \\
\text { Secondary: markers } \\
\text { at I } 2 \text { wk }\end{array}$ & $\begin{array}{l}\text { Significant reduction in hsCRP, } \\
\text { hsTNF- } \alpha \text {, and IL- } 6 \text { with OM + } \\
\text { pravastatin from } 6 \text { wk } \\
\text { No changes in markers with } \\
\text { pravastatin alone }\end{array}$ \\
\hline MORE ${ }^{74}$ & $P, R(2 y r)$ & $\begin{array}{l}\text { OM } 20-40 \mathrm{mg} / \mathrm{d} \\
\text { ATE } 50-100 \mathrm{mg} / \mathrm{d}\end{array}$ & $\begin{array}{l}\text { HTN, high CV risk, } \\
\text { elevated carotid IMT, } \\
\text { and atherosclerotic } \\
\text { plaque (I65) }\end{array}$ & $\begin{array}{l}\text { Common carotid artery } \\
\text { IMT and PV assessed by } \\
\text { noninvasive ultrasound }\end{array}$ & $\begin{array}{l}\text { OM and ATE produced similar } \\
\text { changes in IMT and PV at } 2 \mathrm{yr} \\
\text { Significantly greater } \mathrm{PV} \\
\text { regression with } \mathrm{OM} \text { in patients } \\
\text { with baseline } \mathrm{PV} \geq 33.7 \mu \mathrm{L} \\
(P=0.023 \text { vs } \mathrm{ATE})\end{array}$ \\
\hline $\mathrm{VIOS}^{77}$ & $P, R(I y r)$ & $\begin{array}{l}\text { OM } 20-40 \mathrm{mg} / \mathrm{d} \\
\text { ATE } 50-100 \mathrm{mg} / \mathrm{d} \\
\text { (treat to goal + HCTZ, } \\
\text { amlodipine, or } \\
\text { hydralazine prn) }\end{array}$ & $\begin{array}{l}\text { Stage I HTN (49) } \\
\text { Normal controls (II) }\end{array}$ & $\begin{array}{l}\text { Change in percentage } \\
\text { wall:Iumen ratio of } \\
\text { small resistance vessels } \\
\text { assessed by pressurized } \\
\text { myography }\end{array}$ & $\begin{array}{l}\text { I-year change in wall: } \\
\text { lumen ratio } \\
\text { Significantly reduced with } \\
\text { OM }(14.9 \%-1 \mathrm{I} .1 \% ; P<0.0 \text { I) } \\
\text { No significant change from } \\
\text { baseline with ATE }(P=N S) \\
\text { Controls: II.0\% }\end{array}$ \\
\hline
\end{tabular}

Abbreviations: ATE, atenolol; CAD, coronary artery disease; CCBs, calcium channel blockers; CRP, C-reactive protein; CV, cardiovascular; DB, double-blind; EUTOPIA, European Trial on Olmesartan and Pravastatin in Inflammation and Atherosclerosis; HCTZ, hydrochlorothiazide; hs, high sensitivity; HTN, hypertension; ICAM-I, intracellular adhesion molecule-I; IL, interleukin; IMT, intima-media thickness; IVUS, intravascular ultrasound; MCP, monocyte chemotactic protein; mo, month(s); MORE, Multicenter Olmesartan Atherosclerosis Regression Evaluation; NS, not significant; od, once daily; OLIVUS, Impact of Olmesartan on Progression of Coronary Atherosclerosis: Evaluation by Intravascular Ultrasound; P, prospective; PAV, percent atheroma volume; PLA, placebo; PCI, percutaneous coronary intervention; prn, as needed; PV, plaque volume; R, randomized; TAV, total atheroma volume; TNF, tumor necrosis factor; VIOS, Vascular Improvement with Olmesartan Medoxomil Study; wk, week(s); yr, year(s).

coronary intervention for culprit lesions. ${ }^{73}$ Volumetric IVUS analyses included lumen, plaque, and vessel volume; percent atheroma volume (PAV); and total atheroma volume (TAV). After 14 months of active therapy, IVUS showed a significant decrease in TAV and a significant percentage improvement in PAV in olmesartan medoxomil recipients: $5.4 \%$ vs $0.6 \%$ for TAV and $3.1 \%$ vs $-0.7 \%$ for PAV, for placebo vs olmesartan medoxomil, respectively $(P<0.05$ for all vs placebo; Table 1 and Figure 2). ${ }^{73} \mathrm{BP}$ control was identical between olmesartan medoxomil and placebo (control) groups. OLIVUS demonstrated that olmesartan medoxomil decreased the rate of coronary atheroma progression in patients with stable angina pectoris, independent of BP lowering.

\section{EUTOPIA}

The EUTOPIA (European Trial on Olmesartan and Pravastatin in Inflammation and Atherosclerosis) study was a prospective, double-blind, multicenter trial evaluating the anti-inflammatory effects of olmesartan medoxomil, with or without pravastatin, in 211 patients with hypertension and microinflammation. ${ }^{76}$ Patients were randomized to olmesartan medoxomil or placebo for 12 weeks, with pravastatin added to both treatment arms at week 6 , and hydrochlorothiazide (HCTZ) added as necessary to control BP (Table 1). A panel of vascular inflammation markers was assessed at baseline, 6 weeks (primary endpoint), and 12 weeks. At 6 weeks, olmesartan medoxomil significantly reduced the levels of hsCRP, high-sensitivity TNF- $\alpha$ (hsTNF- $\alpha$ ), IL-6, and monocyte chemotactic protein, whereas placebo had no effect (Table 1 and Figure 3). After 12 weeks, hsCRP, hsTNF- $\alpha$, and IL- 6 were further decreased in the olmesartan medoxomil plus pravastatin arm, but no significant reduction in anti-inflammatory markers was observed with pravastatin alone from weeks 6 to 12. Pravastatin monotherapy significantly reduced LDL-C in both arms. ${ }^{76}$ In the EUTOPIA study, Ang II receptor blockade with olmesartan medoxomil 


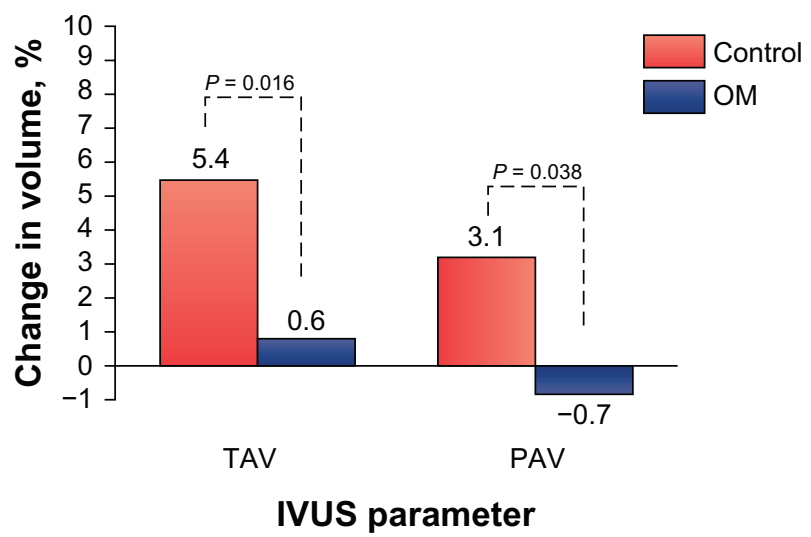

Figure 2 OLIVUS study: change in intravascular ultrasound (IVUS) parameters from baseline to 14-month follow-up. An olmesartan medoxomil (OM)-based treatment regimen significantly decreased total atheroma volume (TAV) and percent change in percent atheroma volume (PAV) as demonstrated by IVUS in patients with stable angina pectoris and native coronary artery disease.

significantly reduced vascular inflammation/inflammatory markers in patients with hypertension.

\section{MORE}

The MORE (Multicenter Olmesartan Atherosclerosis Regression Evaluation) study compared the effect of olmesartan medoxomil vs atenolol on changes in common carotid IMT
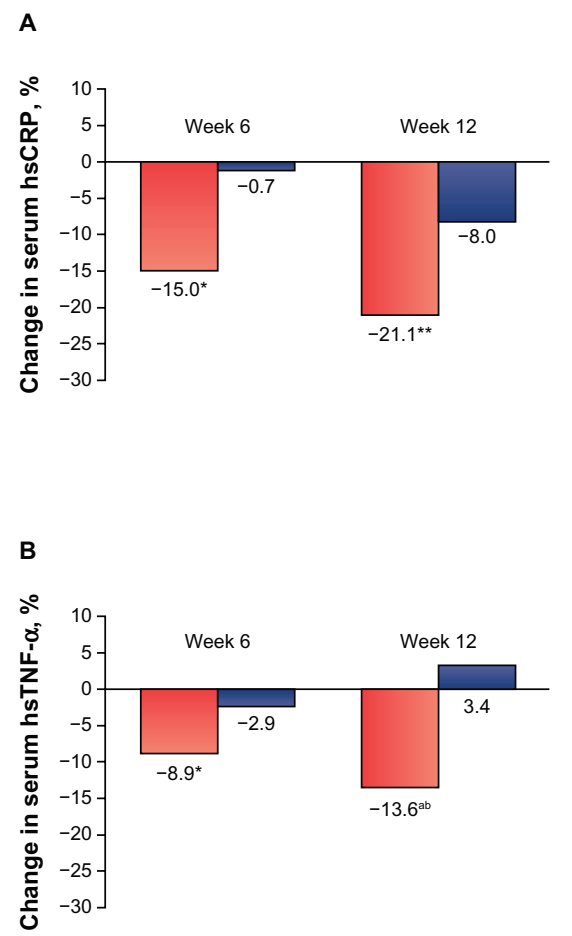

and plaque volume after 2 years of therapy in 165 patients with atherosclerosis. Patients received olmesartan medoxomil $20-40 \mathrm{mg} /$ day or atenolol $50-100 \mathrm{mg} /$ day for 2 years. Twoand three-dimensional ultrasound was used to determine the change from baseline in common carotid IMT and plaque volume, respectively, after 28, 52, and 104 weeks of therapy (Table 1). ${ }^{74}$

Olmesartan medoxomil and atenolol both resulted in similar and significant reductions in carotid IMT. There were no between-treatment differences in plaque volume. In a post hoc analysis in patients with a baseline plaque volume $\geq$ median $(33.7 \mu \mathrm{L})$, plaque volume significantly regressed with olmesartan medoxomil but not with atenolol, even though BP reductions were comparable (Table 1 and Figure 4) ${ }^{74} \mathrm{Com}$ mon carotid IMT and BP decreased similarly with olmesartan medoxomil and atenolol. In addition, there was a preferential reduction in the volume of larger atherosclerotic plaques with olmesartan medoxomil compared with atenolol.

\section{VIOS}

The VIOS (Vascular Improvement With Olmesartan Medoxomil Study) study investigated the impact of RAAS suppression by $\mathrm{AT}_{1}$ receptor blockade on small resistance vessel
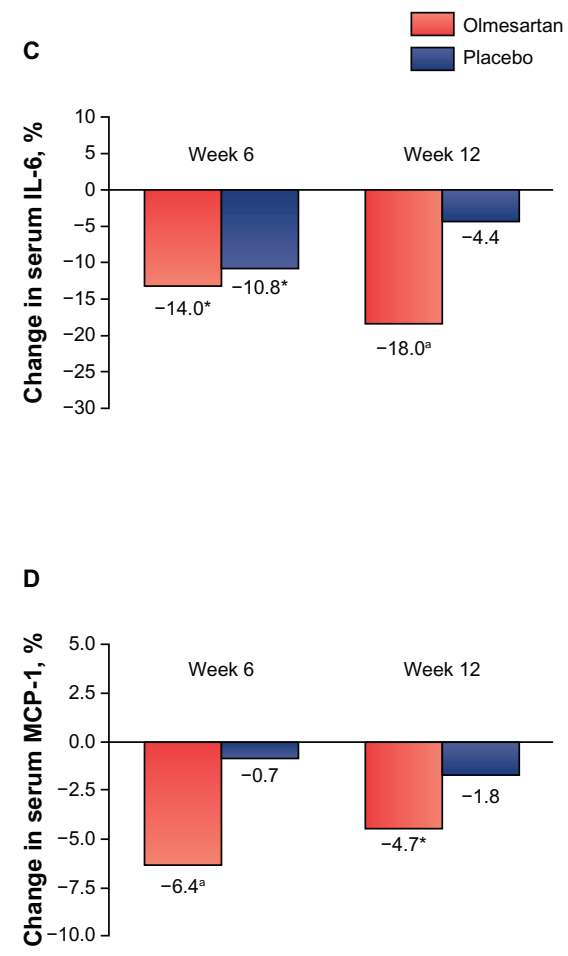

Figure 3 EUTOPIA study: changes in serum concentrations of hsCRP, hsTNF- $\alpha$, IL-6, and MCP-I in patients with essential hypertension after 6 weeks of olmesartan medoxomil therapy or placebo; ${ }^{*} P<0.05$, ${ }^{* *} P<0.02$, a $P<0.01$ vs baseline; ${ }^{b} P<0.05$ olmesartan vs placebo. Olmesartan medoxomil significantly decreased serum levels of high-sensitivity C-reactive protein (hsCRP), high-sensitivity tumor necrosis factor- alpha (hsTNF- $\alpha$ ), interleukin-6 (IL-6), and monocyte chemotactic protein-I (MCP-I) from baseline to week 6. Reductions for placebo were only significant for IL-6 at week 6.

Reprinted with permission from Fliser D, et al. Antiinflammatory effects of angiotensin II subtype I receptor blockade in hypertensive patients with microinflammation. Circulation. 2004; I I0(9): I 103-I 107.76 


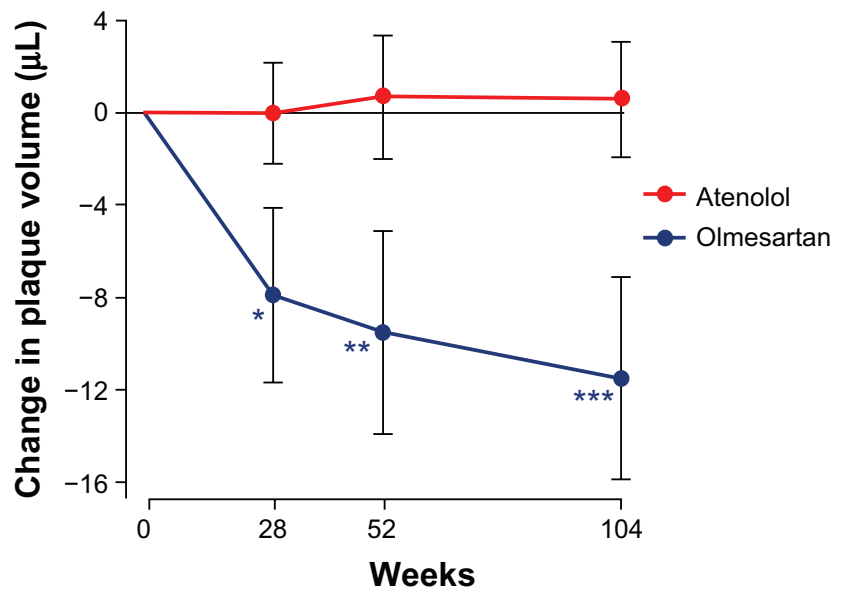

Figure 4 MORE study: post hoc analysis of mean changes in plaque volume at weeks 28,52 , and 104 of follow-up in atenolol- $(n=41)$ and olmesartan- $(n=36)$ treated patients with baseline plaque volume $\geq$ median $(33.7 \mu \mathrm{L})$.

Note: Horizontal bars indicate standard error of the mean; $* P=0.044 ; * * P=0.036$ $* * * P=0.014$ vs baseline.

Reprinted by permission of SAGE from Stumpe KO, et al. Ther Adv Cardiovasc Dis. 2007; I (2):97-106. Copyright (C) by SAGE Publications. ${ }^{74}$

remodeling - an effect thought to provide more complete end-organ protection than BP lowering alone. ${ }^{75}$ Patients with stage 1 hypertension were randomized to olmesartan medoxomil $20-40 \mathrm{mg}$ /day or atenolol 50-100 mg/day plus HCTZ, amlodipine, or hydralazine, as needed, to achieve a BP goal of $<140 / 90 \mathrm{mmHg}$ (Table 1). Subcutaneous gluteal resistance arteries were examined on a pressurized myograph to evaluate remodeling at baseline and after 1 year of active treatment. ${ }^{75}$

Data from VIOS showed that the wall:lumen ratio in arteries obtained from olmesartan medoxomil recipients was significantly reduced $(P<0.01)$ after 1 year of active therapy, whereas no significant change was seen in patients receiving atenolol (Table 1 and Figure 5) ${ }^{77} \mathrm{BP}$ was reduced to a similar level by both agents. VIOS showed that $\mathrm{AT}_{1}$ receptor blockade with olmesartan medoxomil reduced the wall:lumen ratio in resistance arteries in patients with hypertension, independently of BP reduction, and resulted in ratios similar to normotensive controls after 1 year of treatment. ${ }^{77}$ In addition, the augmentation index, a surrogate measure for vascular compliance, was significantly $(P<0.05)$ reduced from baseline with the olmesartan medoxomil-based regimen but not with the atenolol-based regimen. This result provided noninvasive evidence that olmesartan medoxomil improved vascular compliance in association with the aforementioned improvement in resistance vessel morphology.

\section{Summary}

Atherosclerosis is a complex disease that is associated with $\mathrm{CV}$ events including myocardial infarction, unstable angina,

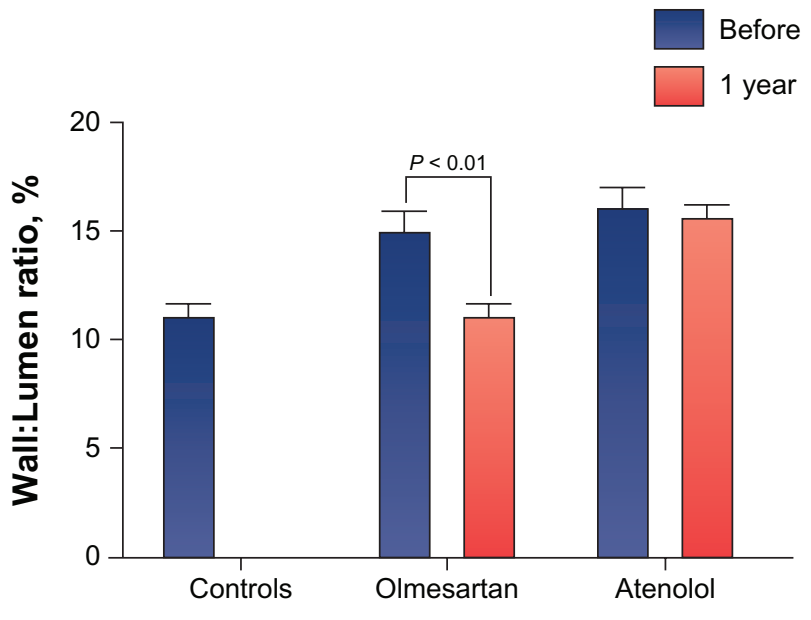

Figure 5 VIOS study: an olmesartan medoxomil regimen significantly reduced the wall:Iumen ratio in arteries to values similar to those observed in normotensive controls at I year of therapy. Conversely, no significant change in wall:Iumen ratio was observed in arteries from atenolol-treated patients.

Reprinted from Smith RD, et al. Reversal of vascular hypertrophy in hypertensive patients through blockage of angiotensin II receptors. J Am Soc Hypertens. 2008;2(3):165-172. Copyright with permission from Elsevier. ${ }^{77}$

and sudden cardiac death, as well as cerebrovascular events and peripheral thromboses. Endothelial dysfunction is a hallmark early event in atherogenesis. Endothelial cells produce a number of vasoactive substances responsible for maintaining vascular tone. Local impairment of the endothelium associated with $\mathrm{CV}$ risk factors creates an imbalance between the normal concentrations of vasodilating and vasoconstricting factors, in particular, an increase in Ang II and a decrease in NO. Impaired NO bioavailability as a consequence of oxidative stress and increased levels of Ang II results in increased vasoconstriction, and both of these processes play key roles in endothelial dysfunction and atherosclerosis. The RAAS, and its primary mediator Ang II, also have a direct influence on the progression of the atherosclerotic process via effects on endothelial function, inflammation, fibrinolytic balance, and plaque stability.

Agents in the ARB, ACEI, and CCB drug classes have demonstrated beneficial effects on the atherosclerotic process. The clinical trial data presented in this review for the ARB olmesartan medoxomil demonstrate anti-atherogenic effects in a range of patient types, as well as provide evidence of slowing atheroma progression, reducing vascular inflammation, decreasing carotid IMT and atherosclerotic plaque volume, and improving the arterial wall:lumen ratio. These data complement the results from several animal model and in vitro studies, which serve to elucidate the mechanisms of the anti-atherogenic effect. The aforementioned clinical changes observed in the olmesartan medoxomil studies may have a beneficial effect on improving endothelial dysfunction 
and, consequently, slowing atherogenesis. Although longterm CV outcomes were not assessed in these studies, the observed changes provide a rationale for prospective trials to ascertain the role of olmesartan medoxomil in reducing the risk or severity of CVD.

\section{Conclusion}

Certain antihypertensive agents have been shown to effectively slow the process of atherogenesis in clinical evaluations. Both ARBs and ACEIs affect the RAAS directly, either by blocking the binding of Ang II to the AT 1 receptor or by decreasing production of Ang II. These RAAS antagonists, as well as certain dihydropyridine CCBs, possess both ancillary and synergistic effects that increase NO bioavailability, reduce oxidative stress, and/or suppress RAAS-associated inflammatory response, as shown by the effect of such agents on a range of inflammatory markers. These changes bring about an improvement in endothelial activity and vascular function, and may additionally be associated with benefits beyond BP lowering in the treatment of patients with atherosclerosis and hypertension.

Data from the olmesartan medoxomil clinical trials OLIVUS, EUTOPIA, VIOS, and MORE have demonstrated the specific utility of RAAS suppression in reducing atherosclerotic plaque volume, improving plaque composition and stability, and in improving endothelial dysfunction. These studies have shown that olmesartan medoxomil treatment may slow the progression of atherosclerosis, thereby potentially improving CV outcomes.

\section{Acknowledgments}

Medical writing assistance was provided by Alan J Klopp, $\mathrm{PhD}$, and Mary Hines of inScience Communications, a Wolters Kluwer Business, and funded by Daiichi Sankyo, Inc.

\section{Disclosures}

Dr Mason did not receive any compensation for the preparation of this manuscript.

\section{References}

1. Roger VL, Go AS, Lloyd-Jones DM, et al. Heart disease and stroke statistics - 2011 update: a report from the American Heart Association. Circulation. 2011;123(4):e18-e209.

2. Galkina E, Ley K. Immune and inflammatory mechanisms of atherosclerosis (*). Аппи Rev Immunol. 2009;27:165-197.

3. Scott J. The pathogenesis of atherosclerosis and new opportunities for treatment and prevention. J Neural Transm Suppl. 2002;(63):1-17.

4. Wasserman BA. Clinical carotid atherosclerosis. Neuroimaging Clin $N$ Am. 2002;12(3):403-419.

5. Li JJ, Chen JL. Inflammation may be a bridge connecting hypertension and atherosclerosis. Med Hypotheses. 2005;64(5):925-929.
6. Rosenfeld ME. An overview of the evolution of the atherosclerotic plaque: from fatty streak to plaque rupture and thrombosis. $Z$ Kardiol. 2000;89(Suppl 7):2-6.

7. Matsushita M, Nishikimi N, Sakurai T, Nimura Y. Relationship between aortic calcification and atherosclerotic disease in patients with abdominal aortic aneurysm. Int Angiol. 2000;19(3):276-279.

8. Kramer CM, Anderson JD. MRI of atherosclerosis: diagnosis and monitoring therapy. Expert Rev Cardiovasc Ther. 2007;5(1): 69-80.

9. Brunner H, Cockcroft JR, Deanfield J, et al. Endothelial function and dysfunction. Part II: association with cardiovascular risk factors and diseases. A statement by the Working Group on Endothelins and Endothelial Factors of the European Society of Hypertension. J Hypertens. 2005;23(2):233-246.

10. Standridge JB. Hypertension and atherosclerosis: clinical implications from the ALLHAT trial. Curr Atheroscler Rep. 2005;7(2): 132-139.

11. Ross R. Atherosclerosis - an inflammatory disease. $N$ Engl $J$ Med. 1999;340(2):115-126.

12. Dzau V, Braunwald E. Resolved and unresolved issues in the prevention and treatment of coronary artery disease: a workshop consensus statement. Am Heart J. 1991;121(4 Pt 1):1244-1263.

13. Deanfield J, Donald A, Ferri C, et al. Endothelial function and dysfunction. Part I: methodological issues for assessment in the different vascular beds: a statement by the Working Group on Endothelin and Endothelial Factors of the European Society of Hypertension. J Hypertens. 2005;23(1):7-17.

14. Hwang SJ, Ballantyne CM, Sharrett AR, et al. Circulating adhesion molecules VCAM-1, ICAM-1, and E-selectin in carotid atherosclerosis and incident coronary heart disease cases: the Atherosclerosis Risk In Communities (ARIC) study. Circulation. 1997;96(12):4219-4225.

15. Ferrario CM, Strawn WB. Role of the renin-angiotensin-aldosterone system and proinflammatory mediators in cardiovascular disease. $\mathrm{Am}$ J Cardiol. 2006;98(1):121-128.

16. Gronholdt ML, Dalager-Pedersen S, Falk E. Coronary atherosclerosis: determinants of plaque rupture. Eur Heart J. 1998;19(Suppl C): $\mathrm{C} 24-\mathrm{C} 29$

17. Koenig W, Khuseyinova N. Biomarkers of atherosclerotic plaque instability and rupture. Arterioscler Thromb Vasc Biol. 2007;27(1):15-26.

18. Libby P. Changing concepts of atherogenesis. J Intern Med. 2000; 247(3):349-358.

19. Sakariassen KS, Barstad RM. Mechanisms of thromboembolism at arterial plaques. Blood Coagul Fibrinolysis. 1993;4(4):615-625.

20. Katsuda S, Kaji T. Atherosclerosis and extracellular matrix. $J$ Atheroscler Thromb. 2003;10(5):267-274.

21. Theroux P, Fuster V. Acute coronary syndromes: unstable angina and non-Q-wave myocardial infarction. Circulation. 1998;97(12): 1195-1206.

22. Briasoulis A, Tousoulis D, Antoniades C, Stefanadis C, Papageorgiou N. The role of endothelial progenitor cells in vascular repair after arterial injury and atherosclerotic plaque development. Cardiovasc Ther. April 7, 2010. [Epub ahead of print].

23. Varagic J, Trask AJ, Jessup JA, Chappell MC, Ferrario CM. New angiotensins. J Mol Med. 2008;86(6):663-671.

24. Weiss D, Sorescu D, Taylor WR. Angiotensin II and atherosclerosis. Am J Cardiol. 2001;87(8 A):25C-32C.

25. Ruiz-Ortega M, Ruperez M, Esteban V, et al. Angiotensin II: a key factor in the inflammatory and fibrotic response in kidney diseases. Nephrol Dial Transplant. 2006;21(1):16-20.

26. Matsumoto K, Morishita R, Tomita N, et al. Improvement of endothelial dysfunction by angiotensin II blockade accompanied by induction of vascular hepatocyte growth factor system in diabetic spontaneously hypertensive rats. Heart Vessels. 2003;18(1):18-25.

27. da Cunha V, Martin-McNulty B, Vincelette J, et al. Angiotensin II induces histomorphologic features of unstable plaque in a murine model of accelerated atherosclerosis. J Vasc Surg. 2006;44(2): 364-371. 
28. David S, Kumpers P, Lukasz A, Kielstein JT, Haller H, Fliser D. Circulating angiopoietin-2 in essential hypertension: relation to atherosclerosis, vascular inflammation, and treatment with olmesartan/pravastatin J Hypertens. 2009;27(8):1641-1647.

29. Mason RP. Nitric oxide mechanisms in the pathogenesis of global risk. J Clin Hypertens (Greenwich). 2006;8(8 Suppl 2):31-38; quiz 40.

30. Singh U, Jialal I. Oxidative stress and atherosclerosis. Pathophysiology. 2006;13(3):129-142

31. Taddei S, Virdis A, Ghiadoni L, Magagna A, Salvetti A. Vitamin $\mathrm{C}$ improves endothelium-dependent vasodilation by restoring nitric oxide activity in essential hypertension. Circulation. 1998;97(22): 2222-2229.

32. Bautista LE. Inflammation, endothelial dysfunction, and the risk of high blood pressure: epidemiologic and biological evidence. J Hum Hypertens. 2003;17(4):223-230.

33. Touyz RM, Schiffrin EL. Reactive oxygen species in vascular biology: implications in hypertension. Histochem Cell Biol. 2004;122(4): 339-352.

34. Gibbons GH. Endothelial function as a determinant of vascular function and structure: a new therapeutic target. Am J Cardiol. 1997;79(5A): 3-8.

35. Panza JA, Quyyumi AA, Brush JE Jr, Epstein SE. Abnormal endothelium-dependent vascular relaxation in patients with essential hypertension. N Engl J Med. 1990;323(1):22-27.

36. Mizuno Y, Jacob RF, Mason RP. Advances in pharmacologic modulation of nitric oxide in hypertension. Curr Cardiol Rep. 2010; 12(6):472-480.

37. Ferrario CM, Strawn WB. Targeting the RAAS for the treatment of atherosclerosis. Drug Discov Today Ther Strateg. 2005;2(3):221-229.

38. Hammoud RA, Vaccari CS, Nagamia SH, Khan BV. Regulation of the renin-angiotensin system in coronary atherosclerosis: a review of the literature. Vasc Health Risk Manag. 2007;3(6):937-945.

39. Mizuno Y, Jacob RF, Mason RP. Effects of calcium channel and renin-angiotensin system blockade on intravascular and neurohormonal mechanisms of hypertensive vascular disease. Am J Hypertens. 2008;21 (10):1076-1085.

40. Yusuf S, Sleight P, Pogue J, Bosch J, Davies R, Dagenais G. Effects of an angiotensin-converting-enzyme inhibitor, ramipril, on cardiovascular events in high-risk patients. The Heart Outcomes Prevention Evaluation Study Investigators. $N$ Engl J Med. 2000;342(3):145-153.

41. Pitt B, Byington RP, Furberg CD, et al. Effect of amlodipine on the progression of atherosclerosis and the occurrence of clinical events. PREVENT Investigators. Circulation. 2000;102(13):1503-1510.

42. Nissen SE, Tuzcu EM, Libby P, et al. Effect of antihypertensive agents on cardiovascular events in patients with coronary disease and normal blood pressure: the CAMELOT study: a randomized controlled trial. JAMA. 2004;292(18):2217-2225.

43. Lonn E, Yusuf S, Dzavik V, et al. Effects of ramipril and vitamin E on atherosclerosis: the study to evaluate carotid ultrasound changes in patients treated with ramipril and vitamin E (SECURE). Circulation. 2001;103(7):919-925.

44. Griendling KK, Sorescu D, Ushio-Fukai M. NAD(P)H oxidase: role in cardiovascular biology and disease. Circ Res. 2000;86(5):494-501.

45. Chen CH, Ting CT, Lin SJ, et al. Different effects of fosinopril and atenolol on wave reflections in hypertensive patients. Hypertension. 1995;25(5):1034-1041.

46. Hirata K, Vlachopoulos C, Adji A, O'Rourke MF. Benefits from angiotensin-converting enzyme inhibitor 'beyond blood pressure lowering': beyond blood pressure or beyond the brachial artery? J Hypertens. 2005;23(3):551-556.

47. Mason RP, Walter MF, Trumbore MW, Olmstead EG Jr, Mason PE. Membrane antioxidant effects of the charged dihydropyridine calcium antagonist amlodipine. J Mol Cell Cardiol. 1999;31(1): 275-281.

48. Schmieder RE, Hilgers KF, Schlaich MP, Schmidt BM. Renin-angiotensin system and cardiovascular risk. Lancet. 2007;369(9568):1208-1219.
49. Perrone-Filardi P, Corrado L, Brevetti G, et al. Effects of AT1 receptor antagonism with candesartan on endothelial function in patients with hypertension and coronary artery disease. J Clin Hypertens (Greenwich). 2009;11(5):260-265.

50. Koh KK, Han SH, Chung WJ, et al. Comparison of effects of losartan, irbesartan, and candesartan on flow-mediated brachial artery dilation and on inflammatory and thrombolytic markers in patients with systemic hypertension. Am J Cardiol. 2004;93(11):1432-1435, A1410.

51. Rosei EA, Rizzoni D, Muiesan ML, et al. Effects of candesartan cilexetil and enalapril on inflammatory markers of atherosclerosis in hypertensive patients with non-insulin-dependent diabetes mellitus. $J$ Hypertens. 2005;23(2):435-444.

52. Baguet JP, Asmar R, Valensi P, Nisse-Durgeat S, Mallion JM. Effects of candesartan cilexetil on carotid remodeling in hypertensive diabetic patients: the MITEC study. Vasc Health Risk Manag. 2009;5(1): 175-183.

53. Dasu MR, Riosvelasco AC, Jialal I. Candesartan inhibits toll-like receptor expression and activity both in vitro and in vivo. Atherosclerosis. 2009;202(1):76-83.

54. Bragulat E, Larrousse M, Coca A, de la Sierra A. Effect of longterm irbesartan treatment on endothelium-dependent vasodilation in essential hypertensive patients. Br J Biomed Sci. 2003;60(4): 191-196.

55. von zur Muhlen B, Kahan T, Hagg A, Millgard J, Lind L. Treatment with irbesartan or atenolol improves endothelial function in essential hypertension. J Hypertens. 2001;19(10):1813-1818.

56. Makris TK, Stavroulakis GA, Krespi PG, et al. Fibrinolytic/hemostatic variables in arterial hypertension: response to treatment with irbesartan or atenolol. Am J Hypertens. 2000;13(7):783-788.

57. Sola S, Mir MQ, Cheema FA, et al. Irbesartan and lipoic acid improve endothelial function and reduce markers of inflammation in the metabolic syndrome: results of the Irbesartan and Lipoic Acid in Endothelial Dysfunction (ISLAND) study. Circulation. 2005;111(3): 343-348.

58. Ceriello A, Assaloni R, Da Ros R, et al. Effect of atorvastatin and irbesartan, alone and in combination, on postprandial endothelial dysfunction, oxidative stress, and inflammation in type 2 diabetic patients. Circulation. 2005;111(19):2518-2524.

59. Negro R. Endothelial effects of antihypertensive treatment: focus on irbesartan. Vasc Health Risk Manag. 2008;4(1):89-101.

60. Gomez-Garre D, Martin-Ventura JL, Granados R, et al. Losartan improves resistance artery lesions and prevents CTGF and TGF-beta production in mild hypertensive patients. Kidney Int. 2006;69(7): 1237-1244.

61. Rachmani R, Levi Z, Zadok BS, Ravid M. Losartan and lercanidipine attenuate low-density lipoprotein oxidation in patients with hypertension and type 2 diabetes mellitus: a randomized, prospective crossover study. Clin Pharmacol Ther. 2002;72(3):302-307.

62. Flammer AJ, Hermann F, Wiesli P, et al. Effect of losartan, compared with atenolol, on endothelial function and oxidative stress in patients with type 2 diabetes and hypertension. J Hypertens. 2007;25(4): 785-791.

63. Sonoda M, Aoyagi T, Takenaka K, Uno K, Nagai R. A one-year study of the antiatherosclerotic effect of the angiotensin-II receptor blocker losartan in hypertensive patients. A comparison with angiotension-converting enzyme inhibitors. Int Heart J. 2008;49(1): 95-103.

64. Dandona P, Kumar V, Aljada A, et al. Angiotensin II receptor blocker valsartan suppresses reactive oxygen species generation in leukocytes, nuclear factor-kappa B, in mononuclear cells of normal subjects: evidence of an antiinflammatory action. J Clin Endocrinol Metab. 2003; 88(9):4496-4501.

65. Manabe S, Okura T, Watanabe S, Fukuoka T, Higaki J. Effects of angiotensin II receptor blockade with valsartan on pro-inflammatory cytokines in patients with essential hypertension. J Cardiovasc Pharmacol. 2005;46(6):735-739. 
66. Link A, Lenz M, Legner D, Bohm M, Nickenig G. Telmisartan inhibits beta2-integrin MAC-1 expression in human T-lymphocytes. J Hypertens. 2006;24(9):1891-1898.

67. Brunner HR. Clinical efficacy and tolerability of olmesartan. Clin Ther. 2004;26(Suppl A):A28-A32.

68. Neutel JM, Kereiakes DJ. An olmesartan medoxomil-based treatment algorithm is effective in achieving 24-hour BP control in patients with type 2 diabetes mellitus, regardless of age, race, sex, or severity of hypertension: subgroup analysis of the BENIFICIARY study. Am J Cardiovasc Drugs. 2010;10(5):289-303.

69. Oparil S, Pimenta E. Efficacy of an olmesartan medoxomil-based treatment algorithm in patients stratified by age, race, or sex. J Clin Hypertens (Greenwich). 2010;12(1):3-13.

70. Kyotani Y, Zhao J, Tomita S, et al. Olmesartan inhibits angiotensin II-induced migration of vascular smooth muscle cells through Src and mitogen-activated protein kinase pathways. J Pharmacol Sci. 2010;113 (2): $161-168$.

71. Shimada K, Murayama T, Yokode M, Kita T, Fujita M, Kishimoto C. Olmesartan, a novel angiotensin II type 1 receptor antagonist, reduces severity of atherosclerosis in apolipoprotein E deficient mice associated with reducing superoxide production. Nutr Metab Cardiovasc Dis. April 14, 2010. [Epub ahead of print].

72. Takai S, Jin D, Sakaguchi M, Muramatsu M, Miyazaki M. The regressive effect of an angiotensin II receptor blocker on formed fatty streaks in monkeys fed a high-cholesterol diet. J Hypertens. 2005;23(10): 1879-1886.
73. Hirohata A, Yamamoto K, Miyoshi T, et al. Impact of olmesartan on progression of coronary atherosclerosis: a serial volumetric intravascular ultrasound analysis from the OLIVUS (impact of olmesarten on progression of coronary atherosclerosis: evaluation by intravascular ultrasound) trial. J Am Coll Cardiol. 2010;55(10): 976-982.

74. Stumpe KO, Agabiti-Rosei E, Zielinski T, et al. Carotid intima-media thickness and plaque volume changes following 2-year angiotensin IIreceptor blockade. The Multicentre Olmesartan atherosclerosis Regression Evaluation (MORE) study. Ther Adv Cardiovasc Dis. 2007;1(2): 97-106.

75. Smith RD, Yokoyama H, Averill DB, et al. The protective effects of angiotensin II blockade with olmesartan medoxomil on resistance vessel remodeling (the VIOS study): rationale and baseline characteristics. $\mathrm{Am}$ J Cardiovasc Drugs. 2006;6(5):335-342.

76. Fliser D, Buchholz K, Haller H. Antiinflammatory effects of angiotensin II subtype 1 receptor blockade in hypertensive patients with microinflammation. Circulation. 2004;110(9):1103-1107.

77. Smith RD, Yokoyama H, Averill DB, Schiffrin EL, Ferrario CM. Reversal of vascular hypertrophy in hypertensive patients through blockade of angiotensin II receptors. J Am Soc Hypertens. 2008;2(3): 165-172.
Vascular Health and Risk Management

\section{Publish your work in this journal}

Vascular Health and Risk Management is an international, peerreviewed journal of therapeutics and risk management, focusing on concise rapid reporting of clinical studies on the processes involved in the maintenance of vascular health; the monitoring, prevention and treatment of vascular disease and its sequelae; and the involvement of

\section{Dovepress}

metabolic disorders, particularly diabetes. This journal is indexed on PubMed Central and MedLine. The manuscript management system is completely online and includes a very quick and fair peer-review system, which is all easy to use. Visit http://www.dovepress.com/ testimonials.php to read real quotes from published authors. 